\title{
Dwelling Time pada Sistem dan Prosedur Penanganan Peti Kemas dengan Aplikasi Cost Terminal Operation System di Terminal Peti Kemas Semarang
}

\author{
Riyanto $^{\text {a }}$, R.A.J Susilo Hadi Wibowo ${ }^{b}$, Fajar Transelasi ${ }^{c}$, Dewi Kartika Sari ${ }^{d^{*}}$ \\ a,b,c,d Politeknik Ilmu Pelayaran Semarang \\ aEmail: riyanto@pip-semarang.ac.id \\ ${ }^{\text {b}}$ Email: susilo@pip-semarang.ac.id \\ 'Email: fajartranselasi@ymail.com \\ d*Email: dewikartika@pip-semarang.ac.id
}

\begin{abstract}
ABSTRAK
Sistem kinerja pada terminal peti kemas di Semarang Container Terminal (SCT) belum baik, hal ini dapat dilihat dari $d w e l l i n g$ time yang rata-rata masih lama. Optimalisasi $d w e l l i n g$ time perlu dilakukan supaya mendapatkan keseimbangan proyeksi kenaikan pada saat dagang dan sebagai kompensasi berbagai keterbatasan fasilitas terminal dan infrastruktur. Salah satunya adalah prosedur penanganan peti kemas dengan menggunakan sebuah aplikasi yaitu aplikasi Cost Terminal Operation System. Dengan metode deskriptif kualitatif, maka akan dijelaskan tentang dwelling time dan prosedur penanganan peti kemas dengan aplikasi Cost Terminal Operation System dan dengan metode kuantitatif digunakan untuk mengetahui seberapa besar pemanfaatan dengan adanya terminal kendaraan dengan menggunakan rumus. Terdapat adanya pengaruh positif yang sangat signifikan dari dwelling time terhadap pendapatan pelabuhan. Lamanya dwelling time ini diakibatkan karena beberapa faktor seperti tingginya volume/permintaan impor yang menimbulkan antrean saat prosedur pemeriksaan, tidak dapat berfungsinya sistem selama 24 jam pada prosedur pemeriksaan, kondisi cuaca, dan kesiapan importir. Dengan implementasi sistem ini akan ada percepatan waktu dwelling time sehingga menguntungkan importir dan dampak yang ditimbulkan oleh dwelling time peti kemas setelah penggunaan aplikasi Cost Terminal Operation System adalah waktu tunggu bisa ditekan.
\end{abstract}

Kata Kunci: aplikasi, dwelling time, peti kemas, sistem

\begin{abstract}
The performance system at the container terminal at Semarang Container Terminal (SCT) is not yet good, it can be seen from the average dwelling time which is still long. Dwelling time optimization needs to be done in order to get a balance of projected increases during trading and to compensate for the various limitations of terminal facilities and infrastructure. One of them is the container handling procedure using an application, namely the Cost Terminal Operation System application. With the qualitative descriptive method, the dwelling time and container handling procedures will be explained using a cost terminal operation system application and the quantitative method is used to find out how much use is in the presence of a vehicle terminal using the formula. There is a very significant positive effect of dwelling time on port revenue. The long dwelling time is due to several factors, such as high volume/import demand which causes queues during the inspection procedure, 24-hour system inability to perform inspection procedures, weather conditions, and importer readiness. By implementing this system there will be an acceleration of the dwelling time so that Beneficial to importers and the impact caused by container dwelling time after using the cost terminal operation system application is that the waiting time can be reduced.
\end{abstract}

Keywords: application, dwelling time, container, sistem 


\section{PENDAHULUAN}

Globalisasi memiliki pengaruh penting terhadap beberapa aspek, terutama perekonomian suatu negara (Santosa, 2004; Sasmita, 2015). Faktor penting dalam persaingan ekonomi integritas nasional adalah sistem pengangkutan laut yang efisien dan terkendala dengan baik. Penanganan container yang menghabiskan banyak waktu menunggu di lapangan penumpukan merupakan salah satu faktor signifikan yang menaikkan biaya pelayaran (Yunianto et al., 2018). Indonesia belum memiliki sistem pelabuhan dengan kinerja yang baik (Adris.A.Putra \& Djalante, 2011), sedangkan kinerja sektor pelabuhan memiliki peran yang sangat penting bagi perekonomian nasional. Perdagangan dunia saat ini sebagai besar diangkut melalui laut (seaborne trade) (Biro Komunikasi dan Informasi Publik, 2018). Sejak tahun 2007 hingga tahun 2011 perdagangan dunia mengalami peningkatan setiap tahunnya sebesar 4,8\% hingga mencapai 9.54 miliar ton. Peningkatan ini diakibatkan oleh sistem perdagangan multilateral (Sasmita, 2015). Industri pelayaran merespon peningkatan tersebut dengan membangun kapal-kapal baru khususnya untuk kapal jenis container (peti kemas). Sebanyak 10.053 unit kapal telah dipesan, dengan kapasitas total 495 juta $D W T, 22$ juta $D W T$ dan diantaranya merupakan kapal peti kemas. Peningkatan kegiatan export dan import Indonesia yang seiring dengan pertumbuhan jumlah kapal peti kemas merupakan kabar baik bagi perekonomian nasional yang sekaligus menjadi peringatan bagi Semarang Container Terminal (SCT) dalam hal penanganan peti kemas (Adris.A.Putra \& Djalante, 2011; Patiung et al., 2018). Di SCT, dwelling time atau waktu pengendapan rata-rata peti kemas impor di pelabuhan sejak sebuah peti kemas dibongkar mulai dari kapal menuju peti kemas keluar dari gerbang terminal peti kemas adalah 5 sampai 7 hari. Lebih https://doi.org/10.46484/db.v2i1.247 buruk jika dibanding negara kawasan yang setara seperti Singapura (1,1 hari), Malaysia (3 hari), dan bahkan Thailand (4 hari). Optimalisasi dwelling time perlu dilakukan supaya mendapatkan keseimbangan proyeksi kenaikan perdagangan dan sebagai kompensasi atas berbagai keterbatasan fasilitas terminal dan infrastruktur (Rafi \& Purwanto, 2016). Salah satunya yaitu prosedur penanganan peti kemas dengan menggunakan sebuah aplikasi. Penelitian ini diperlukan jika izin meraih manfaat maksimal dari peluang yang diinginkan oleh pesatnya pertumbuhan ekonomi agar performa dwelling time sebagai pelabuhan masa depan dapat "diukur" dan selanjutnya dioptimasi.

Sepanjang tahun kedatangan peti kemas di SCT mengalami fluktuasi mengikuti perkembangan perdagangan dalam dan luar negeri (Saputra, 2017). Penumpukan peti kemas yang cukup lama terutama di lapangan penumpukan terjadi saat puncak arus peti kemas, dengan demikian peran strategis TPKS untuk menjamin kelancaran arus penanganan peti kemas di pelabuhan dapat terganggu. Untuk itu dalam penelitian ini dikemukakan beberapa tujuan penelitian, yaitu: mendeskripsikan sistem dan prosedur penanganan peti kemas menggunakan aplikasi Cost Terminal Operation System di Terminal Peti Kemas Semarang, mengetahui seberapa lama dwelling time peti kemas di terminal peti kemas Semarang sebelum dan sesudah menggunakan aplikasi Cost Terminal Operation System di Terminal Peti Kemas Semarang, dan mendeskripsikan dampak yang ditimbulkan oleh dwelling time peti kemas setelah penggunaan aplikasi Cost Terminal Operation.

\section{METODE}

Lokasi penelitian ini adalah di Pelabuhan Indonesia III Tanjung Emas Semarang tepatnya pada Kantor Terminal Peti Kemas Pelabuhan 
Tanjung Emas Semarang. Adapun waktu penelitian telah dilaksanakan selama kurang lebih 8 (delapan) bulan yaitu mulai awal Februari sampai dengan akhir September 2020.

Untuk memperoleh data yang diperlukan dalam penelitian ini, penulis menggunakan beberapa metode penelitian kepustakaan, penelitian lapangan (field research), wawancara dengan Bapak Prasetyo sebagai Asisten Manajer Operasional TPKS, yang mengetahui banyak tentang obyek yang sedang diteliti. Peneliti juga melakukan observasi dengan cara mengamati secara langsung obyek yang sedang diteliti di Terminal Peti kemas Semarang (Pelindo III), dokumentasi, dengan cara mengambil langsung data dan dokumen berkaitan dengan obyek penelitian, serta data series yang diperoleh dan dianalisis melalui Dinas Perencanaan dan Administrasi Operasi TPKS.

\section{HASIL DAN PEMBAHASAN}

Dwelling time yaitu waktu yang dihitung dari suatu peti kemas (container) dimuat (loading) dan dibongkar (unloading) dari kapal menuju ke peti kemas tersebut pergi dari terminal melalui dermaga utama (Anita \& Asmadewa, 2017). Pada saat ini, tingkat dwelling time yang sedang dihadapi pada pelabuhan-pelabuhan di Indonesia sangat tinggi. Rata-rata dwelling time di Indonesia adalah kisaran 5 hingga 7 hari. Waktu tersebut sangatlah lama dibandingkan dengan dwelling time di beberapa negara seperti Hong Kong yaitu 2 hari, Singapura yang hanya 1,5 hari, Leam Chabang di Thailand 5 hari, Australia 3 hari, dan Port Klang di Malaysia 4 hari.

Beberapa faktor yang sangat dapat memengaruhi lamanya dari dwelling time yaitu adanya kapasitas lahan penumpukan, fasilitas bongkar/muat yang dipergunakan oleh masing-masing operator terminal, tingkat kepadatan dari arus bongkar muat peti kemas yang ditangani, dan sebagainya. Tingginya tingkat tunggu bongkar muat pelabuhan di Indonesia berpengaruh ke sektor perekonomian negara (Gultom, 2017). Industri di dalam negeri yang dikhususkan ekspor ke luar negeri akan cenderung menemukan hambatan dalam hal produktivitasnya.

Para pelaksana yang berkepentingan terlibat dalam alur logistik peti kemas ini diantaranya: perusahaan freight forwarder, operator terminal peti kemas, pengelola gudang penyangga (depo dan TPS), perusahaan truk, Perusahaan Pengurusan Jasa Kepabeanan (PPJK), agen pelayaran, dan termasuk unsur pemerintah terkait (bea cukai, karantina, dan sebagainya).

1. Kegiatan bongkar/muat kapal proses sandar kapal

a. Perencanaan kapal membuat "berthing window" berdasarkan berthing contract sebagian dari pemasaran yang merupakan layanan kapal yang dilayani dan dialokasikan waktunya dalam setiap minggu berdasarkan ketersediaan dermaga.

b. Perencanaan untuk membuat "berthing plan" untuk dialokasikan dermaga mengacu kepada "berthing window" dan berdasarkan dari data yang diterima dari "shipping line" (perusahaan pelayaran).

c. Agen/perusahaan pelayaran menginformasikan rencana kedatangan kapal kepada bagian terminal peti kemas, selambatlambatnya 1 x 24 jam sebelum kapal tiba.

2. Dokumen dari permohonan bongkar/muat:

a. Container Vessel Identification Advice (CVIA), memberitahukan rencana kegiatan saat kapal di terminal.

b. EDI Baplie, data informasi tentang posisi peti kemas di kapal.

c. Daftar container dengan penanganan khusus.

d. Data Kapal.

e. Gambar stowage kapal. 
3. Mengadakan rapat delapan jam sebelum kapal menepi ke pelabuhan dilaksanakan pada bagian perencanaan yang membahas bagaimana urutan-urutan sandarnya kapal berdasarkan master cable dengan prioritas utama dan weekly ship's schedule:

a. Menentukan Estimate Time Departure (ETD) dan Estimate Time Berthing (ETB);

b. Posisi sandarnya kapal, posisi kade meter tempat sandar;

c. Jumlah peti kemas yang akan dibongkar/muat;

d. Permintaan tenaga kerja bongkar muat (TKBM);

e. Kegiatan dari bongkar/impor (stevedoring \& cargodoring).

f. Kesiapan dan kebutuhan dari peralatan bongkar/muat;

g. Penetapan pada saat closing time;

h. Kesiapan dan kebutuhan dari lapangan penumpukan;

i. Pihak dari kepanduan akan melakukan pemanduan dan penarikan kapal, guna akan dilakukannya penyandaran di kade yang sudah ditentukan;

j. Pelabuhan dari perusahaan bongkar/muat juga akan menginput beberapa rencana penyandaran dan beberapa rencana kerja bongkar/muat di Inaportnet berdasarkan dari data yang telah dimasukkan oleh shipping lines (perusahaan pelayaran);

k. Shipping lines (perusahaan pelayaran) telah mendaftarkan Rencana Penyandaran Kapal, Operasi (RPKOP) dan Rencana Kerja Bongkar Muat (RKBM) di sistem inaportnet guna untuk mendapatkan permohonan izin sandar dan pelayanan dari kepanduan;

4. Kapal siap dibongkar.

Whiskey yang selalu mengecek dari segel dan kondisi peti kemas, membuat Container Damage Report (CDR) jika ada kemungkinan kerusakan, memperbarui peti kemas ke sistem, jika ada masalah operator Rubber Tyred Gantry (RTG) dibantu pengawas yang berada di lapangan menginformasikan pada pengendalian, memperbarui peti kemas ke dalam sistem dengan pengawasan oleh pengendalian, operator RTG menumpuk peti kemas di lapangan, laporan hasil kegiatan operasi per shift dan time sheet yang sudah diverifikasi oleh petugas yang berwenang akan diserahkan kepada staf bagian operasi untuk dibuatkan laporan hasil kerja lapangan, pembuatan RBM, dan pembuatan invoice.

5. Proses Pengeluaran Peti Kemas (Delivery)

a. Pengeluaran peti kemas impor

1) Setiap petugas gate akan mendapatkan Surat Pengeluaran peti kemas (SP-2) dan akan dilakukan verifikasi. Jika data tidak sesuai maka SP-2 akan dikembalikan ke consignee. Bila sesuai yang dilakukan gate in transaction, dimonitor pengendalian;

2) Setiap petugas di lapangan harus memastikan kesiapan dari personil dan harus menginformasikan ke alat pengendalian. Lift on peti kemas oleh RTG operator, update ke sistem dan dimonitor pengendalian;

3) Setiap petugas gate akan melaksanakan pengecekan segel dan kondisi pada fisik peti kemas serta bagian atas peti kemas melalui monitor CCTV;

4) Truk peti kemas akan diperbolehkan untuk keluar beserta peti kemasnya untuk dibawa ke pabrik (tempat tujuan cargo owner).

b. Proses mengeluarkan peti kemas impor karena dwelling time

1) Peti kemas yang lama menumpuk di lapangan LINI 1 dan sudah melewati batas lebih 
dari 3 hari, maka harus dipindahkan ke TPS LINI 2;

2) Kegiatan seperti ini bisa disebut sebagai overbrengen atau Pindah Lapangan Penumpukan (PLP).

3) Peti kemas dapat dibawa ke TPS LINI 2 setelah keluar dokumen Surat Perintah Pengeluaran Barang (SPPB);

4) Proses pengeluaran sama dengan pengeluaran peti kemas impor;

5) Setelah selesai pembayaran dengan TPS LINI 2, maka peti kemas akan diperbolehkan langsung dibawa ke pabrik tempat tujuan (cargo owner).

Dwelling time peti kemas di terminal peti kemas Semarang dari kurun waktu 7 (tujuh) tahun terakhir dari tahun 2014 s.d. 2020 Rata-rata dwelling time sebagai berikut:

Tabel 1. Dwelling Time Terminal Peti Kemas Semarang

\begin{tabular}{|c|c|c|}
\hline TAHUN & EXPORT & IMPORT \\
\hline 2014 & 3.42 Hari & 7.45 Hari \\
\hline 2015 & 3.11 Hari & 6.42 Hari \\
\hline 2016 & 2.79 Hari & 6.25 Hari \\
\hline 2017 & 2.59 Hari & 5.91 Hari \\
\hline 2018 & 4.98 Hari & 2.37 Hari \\
\hline 2019 & 2.45 Hari & 5.52 Hari \\
\hline 2020 & 5.00 Hari & 2.50 Hari \\
\hline
\end{tabular}

Sumber data : Data diolah, 2014-2020

Untuk tahun 2014 dwelling time pada ekspor rata-rata mencapai 3,42 hari sementara untuk impor rata-rata: 7,45 hari. Tahun 2015 dwelling time pada ekspor mengalami penurunan rata-rata: 00.31 hari menjadi 3.11 hari begitu juga pada dwelling import mengalami mengalami penurunan ratarata: 1,03 hari menjadi; 6,42 hari, untuk tahun 2016 s.d. 2018 mengalami penurunan dwelling time baik ekspor maupun impor, namun untuk tahun 2019 mengalami peningkatan dwelling time ekspor sebanyak: 2.45 hari dan impor sebesar: 5,52 hari disebabkan karena arus peti kemas di terminal peti kemas Pelabuhan Tanjung Emas
Semarang mengalami peningkatan sebesar $8.25 \%$ pada periode yang sama pada tahun 2018, yang disebabkan juga adanya pengurusan dokumen lama di bea dan cukai hingga tahun 2020 (bulan Juli) dwelling time ekspor mencapai 5 hari.

Dari proses dwelling time tersebut, rata-rata mempunyai porsi yang berbeda-beda. Pada tahapan pre clearance mempunyai porsi yang paling tinggi. Hal demikian bukan merupakan rendahnya produktivitas yang dimiliki oleh pihak pelabuhan, tetapi dari lamanya proses pengecekan pada tahap customs clearance, sehingga peti kemas yang telah lama menumpuk (pada tahap pre clearance) harus terpaksa diantrekan kembali untuk jadwal pemeriksaan. Kurangnya dari kinerja bagian bea cukai (dalam proses custom clearance) dalam melaksanakan tanggung jawabnya sangat menjadi kendala yang sering dikeluhkan. Beberapa dari kendala tersebut antara lain: terbatasnya jumlah sumber daya manusia yang tidak dapat dilakukan pekerja selama 24 jam, sedangkan proses bongkar/muat dilakukan selama 24 jam, dan kurangnya infrastruktur yang memadai.

Pendapatan pelabuhan memang cenderung berkurang dibandingkan dengan produktivitas pelabuhan. Di mana pada saat semakin tingginya produktivitas yang dimiliki akan memperoleh pendapatan/hasil yang sebanding. Pendapatan pelabuhan dari bulan ke bulan memang cenderung mengalami fluktuatif yang sifatnya menjadi acak atau tidak tentu. Hal ini terjadi dikarenakan tidak menentunya jumlah peti kemas impor yang masuk melalui PT. Terminal Peti Kemas Semarang.

Dwelling time sangat berpengaruh pada besarnya kapasitas penumpukan serta banyaknya biaya penumpukan. Semakin lama dwelling time pada suatu pelabuhan akan mengakibatkan berkurangnya kapasitas lahan penumpukkan yang tersedia. Pihak dari 
pelabuhan akan menangani masalah ini memiliki solusi yaitu dengan penerapan tarif progresif pada setiap masanya, dengan hal ini diharapkan peti kemas yang telah lama menumpuk agar cepat dikeluarkan daripada dikenakan biaya penumpukan yang cenderung meningkat dari hari ke hari. Biaya penumpukan ini adalah salah satu unsur total pendapatan keseluruhan.

Waktu tunggu peti kemas atau dwelling time pada sejumlah pelabuhan di Indonesia tercatat masih cukup lama, termasuk di Pelabuhan Tanjung Emas Semarang. Sementara pada Januari 2020, dwelling time di Pelabuhan Tanjung Emas mencapai lebih dari 4 hari.

Data tersebut juga mencatatkan Pelabuhan Tanjung Emas sebagai pelabuhan dengan dwelling time terlama. Lamanya waktu tunggu peti kemas dikarenakan pengurusan dokumen, di Terminal Peti Kemas Pelabuhan Tanjung Emas sebenarnya tidak ada antrean kapal. Yang membuat proses lama karena pengurusan dokumennya di bea cukai.

\section{SIMPULAN}

Berdasarkan hasil pembahasan yang telah dikemukakan pada bab sebelumnya maka dapat ditarik kesimpulan sebagai berikut:

1. Sistem dan prosedur penanganan peti kemas menggunakan aplikasi Cost Terminal Operation System sudah diterapkan dengan System Single Submission (SSm) atau sistem pelayanan satu pintu dan Joint Inspection Pabean. Karantina di Pelabuhan Tanjung Emas Semarang. SSM menjadikan importir atau Perusahaan Pengurus Jasa Kepabeanan (PPJK) cukup mengakses satu portal untuk pengajuan dokumen pabean dan karantina sekaligus.

2. Dwelling time peti kemas di terminal peti kemas Semarang sebelum dan sesudah menggunakan aplikasi Cost Terminal Operation System di https://doi.org/10.46484/db.v2i1.247 terminal peti kemas Semarang sangat efektif penerapan sistem ini karena sebelumnya para importir harus mengajukan dua kali perizinan ke bea cukai dan karantina. Dengan implementasi sistem ini akan ada percepatan waktu 2 hari dari sebelumnya 3 hari sehingga menguntungkan importir.

3. Dampak yang ditimbulkan oleh dweling time peti kemas setelah penggunaan aplikasi cost terminal operation waktu tunggu bisa ditekan sehingga dampak dari sisi ekonomi mikro dan makro berdampak terhadap barang import bersaing dengan barang lokal sehingga ekonomi lokal meningkat dan daya saing produk lokal meningkat dibanding produk impor.

Berdasarkan kesimpulan dari penelitian ini peneliti mengemukakan saran-saran sebagai berikut:

1. Sistem dan prosedur penanganan peti kemas menggunakan Aplikasi Cost Terminal Operation System sudah diterapkan dengan System Single Submission (SSm) atau sistem pelayanan satu pintu dan Joint Inspection Pabean Karantina di Pelabuhan Tanjung Emas Semarang. Agar tetap ditingkatkan dan perlu penanganan khusus jika sistem mengalami gangguan off line sehingga pengurusan dokumen secara manual segera dapat ditangani secara tepat dan cepat untuk meminimalisir waktu tunggu yang lama.

2. Diharapkan terus ditingkatkan guna menghindari waktu tunggu yang lama sehingga menguntungkan importir dan menekan nilai jual barang.

3. Diharapkan dengan penggunaan aplikasi Cost Terminal Operation System waktu tunggu bisa ditekan sehingga dampak dari sisi ekonomi mikro dan makro warga meningkat. 


\section{DAFTAR PUSTAKA}

Adris.A.Putra, \& Djalante, S. (2011). Pengembangan Insfrastruktur Pelabuhan Dalam Mendukung Pembangunan Berkelanjutan. Ilmiah Media Engineering Vol.6, 6(2), 84-93.

Anita, S. L., \& Asmadewa, I. (2017). Analisis Dwelling Time Impor Pada Pelabuhan Tanjung Priok Melalui Penerapan Theory of Constraints. Jurnal Perspektif Bea Dan Cukai, 1(1). https://doi.org/10.31092/jpbc.v1i $\underline{1.125}$

Biro Komunikasi dan Informasi Publik. (2018). Empat Puluh Persen Jalur Perdagangan Dunia Melewati Indonesia. Departemen Perhubungan. http://dephub.go.id/post/read/emp at-puluh-persen-jalurperdagangan-dunia-melewatiindonesia

Gultom, E. (2017). Pelabuhan Indonesia sebagai Penyumbang Devisa Negara dalam Perspektif Hukum Bisnis. Kanun: Jurnal Ilmu Hukum, 19(3), 419-444. https://doi.org/10.24815/kanun.v $19 \mathrm{i} 3.8593$

Patiung, R., Darma, R., \& Brasit, N. (2018). Peranan Peti kemas Dalam Menunjang Ekspor Impor Komoditi Hasil Pertanian Di Pelabuhan Soekarno Hatta Makassar. Pasca.Unhas.Ac.Id. http://pasca.unhas.ac.id/jurnal/file s/01e41d4c73974f84977af0487a 43bd3f.pdf

Rafi, S., \& Purwanto, B. (2016). Dwelling Time Management (Antara Harapan dan Kenyataan di Indonesia) Salahudin. Jurnal Manajemen Bisnis Transportasi Dan Logistik (JMBTL), 2(2), 220228.

Santosa, A. B. (2004). Globalisasi dan Perdagangan Internasional.

Saputra, R. (2017). Evaluasi kinerja angkutan peti kemas di terminal peti kemas semarang.
Sasmita, S. (2015). Reformasi Struktur Perdagangan Internasional Dalam WTO: Perspektif Joseph E.Stiglitz. Jurnal Hubungan Internasional, 4(2), 192-203. https://doi.org/10.18196/hi.2015. $\underline{0079.192-203}$

Yunianto, I. T., Nur, H. I., Ardhi, E. W., \& Adhitya, B. P. (2018). Model Evaluasi Trayek Kapal Tol Laut Untuk Maluku dan Papua Bagian Selatan (Evaluation Model of Tol Laut Route for Moluccas and Southern Papua) Irwan Tri Yunianto , Hasan Iqbal Nur, Eka Wahyu Ardhi, Bianca Prima Adhitya Departemen Teknik Transportasi. 